\title{
Random Walk of Security Prices: Empirical Evidence from KSE, LSE, and ISE
}

\author{
Yasir Kamal and Dr. Kashif-Ur-Rehman ${ }^{*}$ \\ SZABIST \\ Islamabad, Pakistan
}

\begin{abstract}
Previously security market research had been focused mainly on developed economies with no attention paid to the security markets of developing countries of South East Asia. In an attempt to fill this gap in the literature, this paper conducts an empirical investigation of the random walk of security prices in Pakistani stock markets. The Augmented Dickey fuller test, Ljung Box $Q$ test, Variance ratio test and a non parametric Run test has been used for analysis of Random walk of security prices. Results indicate the presence of some predictable elements, which contradict with previous studies on Karachi stock market. This is because of the difference in number of observation used in previous studies and this particular study. To conclude, the Karachi stock exchange and Islamabad stock exchange does show a weak random walk of security prices, while Lahore stock exchange show strong random walk of security prices.
\end{abstract}

Keywords: Random Walk of Security Prices, Efficient Market hypothesis, ADF, Run Test, Variance ratio test, Ljung Box Q-statistics.

\section{INTRODUCTION}

The behavior of security prices is one of the affluently documented works in empirical finance; the most enduring model used for this purpose is the random walk hypothesis. The Random Walk Hypothesis has an illustrious history, with remarkable intellectual forbears such as Bachelier, Einstein, L'evy, Kolmogorov, and Wiener. Reference [1] gives first contribution to literature by using random walk hypothesis for financial markets. It was firmly believed amongst financial empiricists that stock market price should reflect the intrinsic value of underlying assets. Over the past two decades ample research work has been undertaken to test the efficient market hypothesis - the claim that a market in which prices fully reflects available information is an efficient one. It was strongly argued that there were no opportunities for investors to make abnormal profits by exploiting information contained in the history of fundamental market data. Reference [2] categorizes three forms of market efficiency: weak, semi-strong and strong. These three forms differ in terms of the types of information which are used in developing investment strategies. As [3] points out, a sufficient condition for weak-form efficiency is that the stock prices fluctuate randomly. As a result; a market is efficient in the weak form if stock prices follow a random walk process.

\footnotetext{
* Bahria University, Islamabad
}

Investors in weak-form efficient markets cannot expect to find any patterns in the historical sequence of stock prices that would provide insight into future price movements and allow them to earn an abnormal rate of return. The security prices fluctuate randomly if a market is efficient, and the degree of randomness of security prices increases with an increase in market efficiency. The most efficient market of all is one in which price changes are completely random and unpredictable. For these reasons, the Random Walk Hypothesis and its close relative, the Efficient Markets Hypothesis, have become icons of modern financial economics that continue to fuel the imagination of academics and investment professionals alike.

Augmented Dickey Fuller Unit Root Test and Serially UnCorrelation Method have been used for the detection of random walk in time series data, see, among others [4], [5], [6] and [7]. Reference [8] shows that common stock prices have properties analogous to the movement of molecules. Osborne applies the methods of statistical mechanics to the stock market, with a detailed analysis of stock price fluctuations from the point of view of a physicist.

Many research works on stock behavior suggest that the expected value of speculative strategies should be zero. In an efficient market the stock prices would reflect all the available information and as a result of different favorable and unfavorable news the stock prices varies differently. These different variations are termed as random movement and in econometric terminology it is called random walk of security prices.

The purpose of this paper is to investigate evidence in support of random walk hypothesis in the Pakistani stock markets (LSE, ISE and KSE) using three techniques: the run test, Augmented Dickey fuller test for unit root, Variance ratio test and Ljung-Box Q test. Of the four tests used, three examine inter temporal structure of stock returns and one examines unit root stationarity in the price revelation process. As [9] points out, if the evidence fails to support weak-form tests there is no reason to examine semi-strong (and/or strong) forms before declaring the market is inefficient on the evidence.

The significance of random walk hypothesis: The significance of the random walk theory can be explained both practically and theoretically. From practical point of view canvasser of the hypothesis deals with the absence or presence of systematic elements in their empirical studies, and the detection of some nonrandom components is not evidence against the RWH unless it can be shown that 
systematic tendencies in past price behavior alone present unexploited opportunities to make above normal profits.

\section{REVIEW OF LITERATURE}

Believer of the efficient-markets concept also tend to espouse the concept of the random walk that the market behaves in discernible way. The advocates of random walk holds that it is impossible to predict the prices of a security from the past performance because changes in economic condition, securities valuations, corporate profits and market as a whole all occur in a myriad of different ways. In random walk process, successive stock returns must be identically distributed and independent so that the correlation between one period's return and the immediate following period is zero, [9], [10], and [11].

So the technical analyst would exploit any non-random fluctuation or speculators would buy before an expected rise in price or sell short before an expected fall in price. In random walk the flow of information is random, and if security prices adjusted with that information so the new security prices would also be randomly attuned, and hence each day securities have different prices depending on the flow of information. And no body can predict about the future security prices. Wall street journal has different thinking on the subject. It believes that past stock prices do show foreseeable trends and that it is possible to forecast the market based on past performance.

So by taking this issue several studies have uncovered empirical evidence, which suggests that stock returns contained predictable components (e.g. see [12], [13] and [14]. Despite these staggering findings their results of failing to reject the random walk applies only to the stock markets of industrialized nations. It is of great interest to explore if the similar patterns can be identified in the Asian stock markets. Reference [15] reports that stock returns of emerging countries are highly predictable and have low correlations with stock returns of developed countries. He suggested that emerging markets are less efficient than developed markets and that higher return and lower risk can be obtained by incorporating emerging market stocks in investor's portfolios. Reference [16] used variance ratio test to find out random walk for Asian stock market and rejected random walk for all the observed Asian stock markets. Reference [17] findings suggested that random walk hypothesis for London stock market is rejected but the weak form of market efficiency can not be rejected. Reference [18] findings suggest that the monthly stock price for the Taiwan stock market exhibits weakform efficiency. Reference [19] used variance ratio test and reject the random walk hypothesis for Latin American stock markets, however run test indicate that Latin American equity markets are weak-form efficient. According to [20] "Thus an accurate statement of the narrow form of the random-walk hypothesis goes as follows: the history of stock price movements contains no useful information that will enable an investor consistently to out perform a buy-and-hold strategy in managing a portfolio".

According to [21], [15] and [22] most of the research has conducted on stock market of developed countries and less attention has been paid to emerging stock markets, so this study is a step toward research on emerging stock markets.

Researchers have consensus that the power of variance ratio test is superfluous than any other test used for random walk [10]. Reference [23] derived the nonoverlapping VR (NVR) statistic, which follows a Beta distribution. As argued by [10], the OVR test is expected to have higher power than the NVR test. The advantages of the VR test are summarized by [24]. The application of the Variance Ratio test to measure the time series data was observed by [25], [26] and [27].

For Karachi stock market [28] observed the random walk of security prices traded in KSE 100 index. [29] took the event of $9 / 11$ and check out the presence of predictable element in stock return, his finding suggested that before 9/11 the predictable element exists in stock returns (e.g. week day effect) but the security prices also followed a random walk. The study about the market efficiency of Karachi stock market [30] suggested that after 9/11, security prices followed a random walk and no calendar related anomalies exist in KSE 100 index.

\section{DATA \& METHODOLOGY}

\subsection{Data}

Daily stock index data was taken for Karachi stock exchange, Lahore stock exchange, and Islamabad stock exchange from Business recorder, which is a well known and reliable source of business indicators in Pakistan. The daily index for all three markets consists of five year data and included almost 1200 observations for each stock market.

\subsection{Measure of Daily Return}

The daily closing value of KSE, LSE and ISE were used for calculating the daily returns. The continuously compounded annual rate of return is a well-accepted approach to measuring the daily returns. The natural log of daily closing index value is, thus the measure of daily return used for this study.

Following is the formula used to find the return:

where:

$$
R_{t}=\operatorname{Ln}\left[\frac{I_{t}}{I_{t-1}}\right]
$$

$\mathrm{R}_{\mathrm{t}}=$ return on day ' $\mathrm{t}$ '

$I_{t}=$ index closing value on day ' $t$ '

$\mathrm{I}_{\mathrm{t}-1}=$ index closing value on day ' $\mathrm{t}-1$ '

$\mathrm{Ln}=$ natural $\log$. 


\subsection{Method and Procedure}

The ADF unit root, Variance ratio test, Ljung Box Q statistics and a non parametric Run test has been used for the analysis of the data. The details of method implemented are given below:

\subsection{Augmented Dickey Fuller (ADF) Unit root test ${ }^{1}$}

The Augmented Dickey Fuller (ADF) unit root test is given as:

$$
\Delta Y_{t}=\beta_{1}+\beta_{2} t+\delta Y_{t-1}+\alpha_{i} \sum_{i=1}^{m} \Delta Y_{t-1}+\varepsilon_{t}^{------~(A) ~}
$$

Where $\varepsilon_{t}$ is a pure white noise error term and where

$$
\begin{aligned}
& \Delta Y_{t-1}=\left(Y_{t-1}-Y_{t-2}\right), \\
& \Delta Y_{t-2}=\left(Y_{t-2}-Y_{t-3}\right), \text { etc. }
\end{aligned}
$$

The number of lagged difference terms to include is often determined empirically, the idea being to include enough terms so that the error term in equation is serially uncorrelated. Since Eq: "A" is a first-order difference equation, so the stability condition requires that $|P|>1$

\subsection{Run Test}

If a series of positive and negative residual occurred, then the randomness of these residual can be checked through runs test which is also known as Geary test, a nonparametric test. The run test determined whether the successive price changes are independent. Unlike to any parametric test the assumption of normal distribution is not applied on run test. If the return series exhibits greater tendency of change in one direction, the average run will be longer and the number of runs fewer than that generated by a random process.

Under the null hypothesis that the successive outcomes are independent and assuming that $\mathrm{N}_{1}>10$ and $\mathrm{N}_{2}>0$, the number of runs is (asymptotically) normally distributed with

Mean: $\quad \mathrm{E}(\mathrm{R})=\frac{2 N_{1} N_{2}}{N}+1$

Variance: $\sigma_{R}^{2}=\frac{2 N_{1} N_{2}\left(2 N_{1} N_{2}-N\right)}{(N)^{2}(N-1)}$

Where $\mathrm{N}=\mathrm{N}_{1}+\mathrm{N}_{2}$

\footnotetext{
1 Decision rule: the computed $\tau$ value should be more negative than the critical $\tau$ value, and the large negative $\tau$ value is generally an indication of stationarity.
}

If the null hypothesis of randomness is sustainable, following the properties of the normal distribution, we should expect that

$\operatorname{Prob}\left[E(R)-1.96 \sigma_{R} \leq R \leq E(R)+1.96 \sigma_{R}\right]=0.95^{2}$

\subsection{Variance Ratio Test}

Lo and MacKinlay variance ratio test is derived on the assumption that if the natural logarithm of a time series $\mathrm{P}_{t}$ is a pure random walk, the variance of its $q^{\text {th }}$ difference grows proportionally with the difference $\mathrm{q}$, that is the variance of its $\mathrm{q}^{\text {th }}$ difference variable would be $\mathrm{q}$ times the variance of its first difference. So if we obtain $n+1$ observations $\mathrm{P}_{\mathrm{o}}, \mathrm{P}_{1}, \mathrm{P}_{2}, \ldots, \mathrm{P}_{\mathrm{n}}$ at equally spaced intervals, $1 / \mathrm{q}$ of the variance of $\mathrm{P}_{\mathrm{t}}, \mathrm{P}_{\mathrm{t}-\mathrm{q}}$ is expected to be the same as the variance of $\mathrm{P}_{t}-\mathrm{P}_{\mathrm{t}-1}$, for a time series characterized by random walks.

The variance ratio, VR (q), is defined as

$\operatorname{VR}(\mathrm{q})=\frac{\sigma_{q}^{2}}{\sigma_{1}^{2}}$

or

$$
\frac{1}{q} \frac{\operatorname{Var}\left(P_{t}-P_{t-q}\right)}{\operatorname{Var}\left(P_{t}-P_{t-1}\right)}=1
$$

Where $\sigma_{q}^{2}$ is the unbiased estimator of 1/q of the variance of qth difference of the logged security return $\left(\mathrm{P}_{\mathrm{t}}-\mathrm{P}_{\mathrm{t}-\mathrm{q}}\right)$ and $\sigma_{1}^{2}$ is an unbiased estimator of the variance of the logged return $\left(\mathrm{P}_{\mathrm{t}}-\mathrm{P}_{\mathrm{t}-1}\right)$. Reference [10] demonstrates that the estimators $\sigma_{q}^{2}$ and $\sigma_{1}^{2}$ can be computed by:

$$
\begin{aligned}
& \sigma_{q}^{2}=\frac{1}{m} \sum_{t=q}^{n}\left(P_{t}-P_{t-q}-q u\right)^{2} \\
& \sigma_{1}^{2}=\frac{1}{n-1} \sum_{t=1}^{n}\left(P_{t}-P_{t-1}-u\right)^{2}
\end{aligned}
$$

Where

$$
\begin{aligned}
& m=q(n q-q+1)\left(1-\frac{q}{n q}\right) \\
& \text { and } \\
& u=\frac{1}{n q}\left(P_{n q}-P_{o}\right)
\end{aligned}
$$

\footnotetext{
2 Decision rule: Do not reject the null hypothesis of randomness with $95 \%$ confidence if $\mathrm{R}$ the number of runs, lies in the preceding confidence interval; reject the null hypothesis if the estimated $\mathrm{R}$ lies outside these limits.
} 
And $\mathrm{P}_{\mathrm{o}}$ and $\mathrm{P}_{\mathrm{nq}}$ are the first and last observations of the time series and $n$ is the sample size. The first test statistic, $\mathrm{Z}(\mathrm{q})$ is derived under the assumption of homoscedasticity, with the asymptotic variance of the VR statistic $\phi(q)$ defined as:

$$
\phi(q)=\frac{2(2 q-1)(q-1)}{3 q(n q)}
$$

And the associated standard $\mathrm{Z}$ test statistic, $\mathrm{Z}(\mathrm{q})$ as:

$$
Z(q)=\frac{V R(q)-1}{\sqrt{\phi(q)}} \rightarrow N(0,1)
$$

There is a growing consensus amongst finance empiricist that volatility is time varying as documented by most of the researchers that variances of most stock returns are conditionally heteroscedastic with respect to time. As a result, a linear relation does not exist over the observation intervals. To overcome this difficulty, Lo and McKinley derive the heteroscedasticity-consistent variance estimator $\phi^{*}(\mathrm{q})$ is given by:

$$
\phi^{*}(\mathrm{q})=\sum_{j=1}^{q}\left[\frac{2(q-j)}{q}\right]^{2} \delta^{\wedge}(j)
$$

Where

$$
\delta^{\wedge}(\mathrm{J})=\frac{\sum_{t=j+1}^{q-1}\left(P_{t}-P_{t-1}-u\right)^{2}\left(P_{t-j}-P_{t-j-1}-\hat{u}\right)^{2}}{\left[\sum_{t=1}^{n q}\left(P_{t}-P_{t-1}-\hat{u}\right)^{2}\right]^{2}}
$$

The VR statistic can be standardized asymptotically to a standard normal test-statistic, $Z^{*}(\mathrm{q})$ which as reported by [10] Lo and McKinley (1988), is computed as:

$\mathrm{Z}^{*}(\mathrm{q})=\frac{V R(q)-1}{\sqrt{\phi^{*}(q)}} \ldots \rightarrow N(0,1)^{3}$

\subsection{Ljung Box-Q Statistics}

The first approach we use here is to consider the autocorrelation structure of stock returns and test the joint significance of the autocorrelation using the Ljung-Box portmanteau statistic (Q). The Ljung-Box Q-statistics are given by:

\footnotetext{
3 Decision Rule: if $Z(q)$ and $Z^{*}(q)$ calculated values is less than $Z$ tabulated values then we reject tabulated $=1.96$ for $5 \%$ significance level.
}

$Q_{L B}=T(T+2) \sum_{j=1}^{k} \frac{r_{j}^{2}}{T-j}$

Where $r_{j}$ is the jth autocorrelation and $T$ is the number of observations. The $\mathrm{Q}$ statistic is often used as a test of whether the series is white noise. Q is asymptotically distributed as a chi square distribution with degree of freedom equal to the number of autocorrelations. This test was developed by Ljung \& Box, in 1979. To compute auto correlation and Ljung-Box Q statistics, we compute correlogram, which graphs the value of auto correlation at successive lags against the length of the lag and the last two columns reported in correlogram are the Ljung-Box Q-statistics and their P values. ${ }^{4}$

\section{DISCUSSION AND ANALYSIS}

\subsection{ADF unit root test}

An Augmented Dickey-Fuller (ADF) test is used for a unit root in time series sample; it is the advance version of the Dickey-Fuller test. The greater the negative value of the ADF test statistic the greater the chance of the rejection of the hypothesis of having a unit root.

From table 1, the ADF test result shows that for all the three stock markets returns, we can reject the null hypothesis of unit root. It was recommended by many financial researchers that existence of random walk component does not mean that future stock return is unpredictable. If stock returns are characterized by a white noise process, the correspondence price indices are said to follow the random walk.

In that case that stock returns are considered to be unpredictable. If the stock returns do not follow white noise or they are integrated of order one or I (1), there exists some predictable components. The ADF is used to find out only the stochastic trend components while the purpose variance ratio approach is to detect if the shortterm fluctuations dominate the stochastic trend components or not. According to [30] the Karachi Stock market follows a random walk for its daily returns, the same results was also determined by [28].

Table 1: ADF Test Results

\begin{tabular}{lrllll}
\hline \hline $\begin{array}{l}\text { ADF } \\
\text { Statistic }\end{array}$ & Test & $\begin{array}{l}R- \\
\text { squared }\end{array}$ & $\begin{array}{l}\text { MacKinnon critical values } \\
\text { for rejection of hypothesis } \\
\text { of a unit root. }\end{array}$ \\
\hline KSE & -34.3 & 0.491 & $1 \%$ Critical Value & -2.56 \\
LSE & -35.5 & 0.507 & $5 \%$ Critical Value & -1.93 \\
ISE & -27.8 & 0.389 & $10 \%$ Critical Value & -1.66 \\
\hline \hline
\end{tabular}

${ }^{4}$ Decision rule: Reject null hypothesis under LB statistics if calculated value of LB is greater than tabulated value of chi square distribution table values with ' $m$ ' d.f. 


\subsection{Non-Parametric Runs Test}

A non-parametric runs test has been commonly used to examine the random walk hypotheses which further implies the existence of weak-form efficiency in stock markets return (e.g. see, [19] and [32] ).

A non-parametric runs test is applicable here as a test of randomness for the sequence of the return. In other words, it tests whether Pakistani stock markets returns are predictable. If the successive change in the returns is random, it is an indication of weak-form efficiency. A test for a run up and down requires dividing the return series into two different types, increasing and decreasing. A positive sign $(+)$ is assigned if the return in the sequence is higher than the preceding return, whereas a negative sign $(-)$ is assigned if the return in the sequence is smaller than the preceding return. A zero (0) is assigned if there is no change in the returns. For example, a series of - - - - + ++ + - - - - $-00000++++$ would indicate five runs-two positive runs of length four, two negative runs of length five and one zero run of length five.

The run-up and run-down test identifies the existence of persistence but does not indicate the direction and degree of persistence. Rejection of the null hypothesis of randomness indicates the persistence in returns does exist, which violates the weak-form of market efficiency.

As suggested in the table 2 that, the successive return for all the markets do not show independence and hence upon the above results we can reject the null hypothesis of randomness which is inconsistent with [30] and [28] study for KSE 100 index.

\subsection{Variance ratio test}

Variance ratio test is developed by [10] and it is more powerful than any standard autocorrelations tools. Under the null hypothesis of variance ratio test the stock return follows a random walk and the variance ratio are expected to be equal to one. Table no.3 reports the estimated variance ratios for lags $q=2,4,8,12,16$, and 20 for both
Table 2

\begin{tabular}{llll}
\hline \hline Runs Test & & & \\
\hline & KSE & LSE & ISE \\
Test Value & 0.001 & 0.002 & 0.001 \\
Cases < Test Value & 584 & 643 & 558 \\
Cases >= Test Value & 638 & 582 & 666 \\
Total Cases & 1222 & 1225 & 1224 \\
Number of Runs & 571 & 571 & 541 \\
Z & -2.282 & -2.349 & -3.87 \\
Asymp. Sig. (2-tailed) & 0.022 & 0.019 & 0.007 \\
\hline \hline
\end{tabular}

homoscedastic and heteroscedastic consistent $Z$ (q) and $Z^{*}(q)$ test statistics.

The table no 3 reported that except LSE (under the assumption of heteroscedasticity) no other stock market returns follows a random walk hypothesis and hence the market efficiency concept was void in this prediction of variance ratio test. As concluded by [30] and [28] the presence of random walk in security price for the KSE 100 index has no more validation under these circumstances. Now to remove these discrepancies in results further theoretical supports are needed.

As for the [28] study is concerned he used the standard tests for autocorrelations, like Ljung Box Q statistics, ADF test for unit root and correlogram method to find the random walk of security prices. So one reason of this discrepancy is that [28] did not use a higher power test like Variance ratio test, the other reason for inconsistency is that [28] used a weekly data for his analysis while in this research daily observation has is used. Now if we see Ljung Box Q statistics of our analysis we can easily conclude that it was consistent with our variance ratio statistic results.

The LB-Q statistics indicate auto correlation for both ISE and KSE but no autocorrelation for LSE at any observe lags. The validity of $Z$ (q) depends to some extent on its asymptotic distribution towards normality and one can

\begin{tabular}{lllllllllll}
\hline \hline & $\mathrm{K}=4$ & $\mathrm{~K}=8$ & $\mathrm{~K}=12$ & $\mathrm{~K}=16$ & $\mathrm{~K}=20$ & $\mathrm{~K}=24$ & $\mathrm{~K}=28$ & $\mathrm{~K}=32$ & $\mathrm{~K}=36$ & $\mathrm{~K}=40$ \\
\hline $\mathrm{KSE}$ & $\mathbf{0 . 2 5 6}$ & $\mathbf{0 . 1 2 0}$ & $\mathbf{0 . 0 8 6}$ & $\mathbf{0 . 0 5 9}$ & $\mathbf{0 . 0 5 1}$ & $\mathbf{0 . 0 4 5}$ & $\mathbf{0 . 0 3 7}$ & $\mathbf{0 . 0 3 1}$ & $\mathbf{0 . 0 2 9}$ & $\mathbf{0 . 0 2 6}$ \\
& $(-13.9)^{*}$ & $(-10.4)^{*}$ & $(-8.52)^{*}$ & $(-7.47)^{*}$ & $(-6.67)^{*}$ & $(-6.09)^{*}$ & $(-5.66)^{*}$ & $(-5.31)^{*}$ & $(-5)^{*}$ & $(-4.75)^{*}$ \\
& $(-7.38)^{*}$ & $(-6.27) *$ & $(-5.49)^{*}$ & $(-5)^{*}$ & $(-4.58)^{*}$ & $(-4.27)^{*}$ & $(-4.05)^{*}$ & $(-3.87)^{*}$ & $(-3.71)^{*}$ & $(-3.58)^{*}$ \\
$\mathrm{LSE}$ & $\mathbf{0 . 2 4 3}$ & $\mathbf{0 . 1 2 3}$ & $\mathbf{0 . 0 8 3}$ & $\mathbf{0 . 0 6 3}$ & $\mathbf{0 . 0 4 2}$ & $\mathbf{0 . 0 3 6}$ & $\mathbf{0 . 0 3 2}$ & $\mathbf{0 . 0 2 9}$ & $\mathbf{0 . 0 2 6}$ & $\mathbf{0 . 2 4 3}$ \\
& $(-14.2)^{*}$ & $(-10.37)^{*}$ & $(-8.56)^{*}$ & $(-7.45)^{*}$ & $(-6.12)^{*}$ & $(-5.67)^{*}$ & $(-5.31)^{*}$ & $(-5.01)^{*}$ & $(-4.75)^{*}$ & $(-14.16)^{*}$ \\
& $(-1.162)$ & $(-1.153)$ & $(-1.15)$ & $(-1.15)$ & $(-1.148)$ & $(-1.147)$ & $(-1.145)$ & $(-1.143)$ & $(-1.141)$ & $(-1.162)$ \\
$\mathrm{ISE}$ & $\mathbf{0 . 2 5 7}$ & $\mathbf{0 . 1 2 4}$ & $\mathbf{0 . 0 9 0}$ & $\mathbf{0 . 0 6 4}$ & $\mathbf{0 . 0 5 4}$ & $\mathbf{0 . 0 4 8}$ & $\mathbf{0 . 0 3 9}$ & $\mathbf{0 . 0 3 6}$ & $\mathbf{0 . 0 3 4}$ & $\mathbf{0 . 0 3 0}$ \\
& $(-13.9)^{*}$ & $(-10.36)^{*}$ & $(-8.48)^{*}$ & $(-7.44)^{*}$ & $(-6.66)^{*}$ & $(-6.07)^{*}$ & $(-5.65)^{*}$ & $(-5.29)^{*}$ & $(-4.98)^{*}$ & $(-4.73)^{*}$ \\
& $(-4.17)^{*}$ & $(-3.99)^{*}$ & $(-3.79)^{*}$ & $(-3.67)^{*}$ & $(-3.54)^{*}$ & $(-3.44)^{*}$ & $(-3.36)^{*}$ & $(-3.28)^{*}$ & $(-3.21)^{*}$ & $(-3.15)^{*}$ \\
\hline \hline
\end{tabular}

The bold $\overline{\overline{\text { numeric }}}$ represents the variance ratio while the values in parenthesis represents the $\mathrm{Z}(\mathrm{q})$ and $\mathrm{Z( \textrm {q } ) * \text { respectively }}$ and the value with a $(*)$ representing the value is significant at $5 \%$. 
also prefer a large sample such as in [30] study more than 2000 daily observations has been taken for analysis for KSE 100 index and only heteroscedastic consistent $Z^{*}$ (q) is free of autocorrelation and indicating randomness.

Since [30] concluded that KSE 100 index is efficient in term of information, so rejection of random walk hypothesis do not imply that market is not efficient. In variance ratio statistic when exceeds one leading to rejection of null hypothesis, which is indication of positive serial correlation that manifest itself in short term fluctuations.

\subsection{Ljung Box Q test}

The LB-Q ${ }^{5}$ statistic is often used as a test of white noise for a time series. LB-Q is asymptotically distributed as a chi square distribution with degree of freedom equal to the number of autocorrelations.

LB-Q statistics obtained for Pakistani stock market returns (shown in Table 4), suggested that there exist autocorrelation for KSE and ISE for few lags but not shows any autocorrelation at any lags for LSE. This result was consistent with not only to previous research work of [30], but also consistent with variance ratio analysis of the same stock markets.

\begin{tabular}{|c|c|c|c|}
\hline & KSE & $L S E$ & ISE \\
\hline Lags & $\begin{array}{c}\text { Q-Stat } \\
\text { (P-value) }\end{array}$ & $\begin{array}{c}\text { Q-Stat } \\
\text { (P-value) }\end{array}$ & $\begin{array}{c}\text { Q-Stat } \\
\text { (P-value) }\end{array}$ \\
\hline 1 & $\begin{array}{c}0.18 \\
(0.67)\end{array}$ & $\begin{array}{c}0.33 \\
(0.56)\end{array}$ & $\begin{array}{c}3.02 \\
(0.08)\end{array}$ \\
\hline 2 & $\begin{array}{c}0.45 \\
(0.80)\end{array}$ & $\begin{array}{c}0.54 \\
(0.76)\end{array}$ & $\begin{array}{c}3.64 \\
(0.16)\end{array}$ \\
\hline 3 & $\begin{array}{c}3.65 \\
(0.30)\end{array}$ & $\begin{array}{c}1.88 \\
(0.60)\end{array}$ & $\begin{array}{c}13.88 \\
(0.003)\end{array}$ \\
\hline 4 & $\begin{array}{c}3.79 \\
(0.43)\end{array}$ & $\begin{array}{c}2.21 \\
(0.69)\end{array}$ & $\begin{array}{c}16.02 \\
(0.003)\end{array}$ \\
\hline 5 & $\begin{array}{l}10.03 \\
(0.07)\end{array}$ & $\begin{array}{c}2.64 \\
(0.75)\end{array}$ & $\begin{array}{c}32.21 \\
(0.00)\end{array}$ \\
\hline
\end{tabular}

\section{CONCLUSION}

In this paper we assessed the random behavior of the security prices for three major Pakistani stock markets i.e. Karachi stock market, Lahore Stock market and Islamabad stock market. To put more validity and accuracy to our analysis, we used a number of statistical models for random walk assessments. These statistical tools started from a non-parametric statistical test i.e. a Run Test,

\footnotetext{
5 The Ljung-Box Q statistic has an asymptotic chi square distribution with $\mathrm{p}$ degrees of freedom equaling the first $\rho$ lags. If the associated probabilities are less than $5 \%$, the null hypothesis of no serial correlation is rejected at $95 \%$ level of confidence.
}

followed by [10] Variance ratio test and L-Jung Box Q statistics. For the assumption of stationarity, the Augmented Dickey Fuller unit root test is also applied.

The analysis section gives us contradictory results from different statistical tools, since some of the tests are more statistically powerful than others ([10] and [33]). That is why we analyzed and interpreted the results with the appropriate assumption and statistical power of the tool used. The Augmented Dickey fuller test of unit root is used only for the existence of unit root in time series data, which suggest the randomness of the observed time series for all the markets. The LB-Q statistic, Run Test and the variance ratio test results were consistent with each other, but LB-Q and VR statistics contradict with RUN test in case of LSE. Our results of KSE also contradict with the general assumption of many researchers who suggested that KSE 100 index follows a Random walk hypothesis, for example [30] and [28].

The Pakistani stock markets follow a random walk hypothesis if the assumption of variance ratio test and LBQ statistic is fulfilled, like large number of observation, etc. One important finding of this result is that although this study contradicts [30], but it is consistent with one part of his study where he argued that in pre 9/11 era KSE 100 index does not follow a random walk and Monday gives a highest positive return which an indication of day of the week effect.

\section{REFERENCES}

[1] Samuelson, Paul (1965). "Proof That Properly Anticipated Prices Fluctuate Randomly", Industrial Management Review, 6, pp. 41-49.

[2] Fama, E.F. (1970) "Efficient capital markets: A review of theory and empirical work", Journal of Finance, 25, 383-417.

[3] McInish, H., and Pulisi, D.J. (1982) "The efficiency of the international money market", Journal of Business Finance and Accounting, 9(2), 167-177.

[4] Barnes, P. (1986), "Thin Trading and Stock Market Efficiency: The Case of the Kuala-Lumpur Stock Exchange", Journal of Business Finance \& Accounting, pp. $609,17$.

[5] Cheung, Wong and Ho (1993), "The Pricing of Risky Assets in two Emerging Asian Markets, Korea and Taiwan", Applied Financial Economics, Vol. 3, No. 4, pp. 315, 24.

[6] Dickinson, J.P. and Muragu, K. (1994) "Market efficiency in developing countries: a case study of the Nairobi Stock Exchange", Journal of Business Finance and Accounting, 21(1), 133-50.

[7] Ayadi, O. and C. Pyun (1994), "An Application of Variance Ratio Test to the Korean Securities Market", Journal of Banking and Finance, Vol. 18, pp. 643 \pm 58.

[8] Osborne, M. F. M. (1962) "Periodic structure in the Brownian motion of the stock market", journal of Operations Research, 10, 345-79. 
[9] Wong, K.A. and Kwong, K.S. (1984) "The behavior of Hong Kong stock Prices", Applied Economics, 16, 905-17

[10] D' Ambrosio, C. (1980) "Random walk and the stock exchange of Singapore", The Financial Review, $1-12$.

[11] Cooper, J.C. (1983) "The Korean stock exchange: a qualitative and quantitative assessment", The Investment Analyst, 70, 5-12.

[12] Fama, E., and K. French, (1988) "permanent and temporary component of stock prices," Journal Political Economy, 96, pp. 246-73.

[13] Lo, A.W. and A.C. MacKinlay, (1989), "The Size and Power of the Variance Ratio Test in Finite Samples: A Monte Carlo Investigation", Journal of Econometrics, 40, 203 - 238.

[14] Keim, D. and Stambough, R. (1986) "Predicting returns in stock and bond markets", Journal of Financial Economics, 17, 357-90.

[15] Harvey, C. (1993), "Portfolio enhancement using emerging markets and conditioning information, working paper World Bank.

[16] Huang (1995), "Do Asian stock market prices follow random walks? Evidence form the variance ratio test" Journal of Applied Financial Economics, 5,251-256.

[18]Fawson, Glover, and Chang (1996) "The weak-form efficiency of the Taiwan share market" journal of Applied Economics Letters, 1996, 3, 663-667

[19] Urrutia (1995),"Test of random walk and market efficiency for Latin American emerging equity market" journal of financial research", vol XVIII, no.3, page 299-309

[20] Malkiel, B, (1995) "Returns from Investing in Equity Mutual Funds 1971 to 1991," Journal of Finance, pp. 549-572.

[21]Errunza, V. and E.Losq, (1985), "The behavior of stock prices on LDC markets", Journal of Banking and Finance, 561-75.
[22] Claessnes, S., S.Dasgupta, and J.Glen, "Stock price behavior in emerging stock markets", working paper, World Bank.

[23] Tian, G., Y. Zhang and W. Huang, (1999), “A Note on the Exact Distributions of Variance Ratio Statistics", Peking University, Mimeo.

[24] Cecchetti, S. G. and Lam, P. S. (1994) "Variance-ratio tests: Small-sample properties with an application to international output data", Journal of Business and Economic Statistics 12, 177-86.

[25] Campbell, J.Y. and N.G. Mankiw, (1987), "Are Output Variations Transitory?" Quarterly Journal of Economics, 102, 857 - 880.

[26] Cogley, T., (1990), "International Evidence on the Size of the Random Walk in Output", Journal of Political Economy, 98, $501-518$.

[27] Poterba, J.M. and L.H. Summers, (1988), "Mean Reversion in Stock Returns: Evidence and Implications", Journal of Financial Economics, 22, 27 $-60$.

[28] Syed, Ali, Abass (2004) "Does KSE 100 index follows a random walk: an empirical study" Social sciences Research Network.

[29] Yasir Kamal, and Zafar Mueen Nasir (2005), “weak day effect in stock return: evidence from Karachi stock exchange" Social Science Research Network.

[30] Yasir Kamal and Kashif Ur Rehman (2005), "weak form of market efficiency: evidence from Karachi stock exchange" Social Science Research Network.

[31] Ljung, G.M. and G.E.P. Box (1978),'On a measure of Lack of Fit in Time series models" Biometrika, Vol.66, pp. 297-303

[32]Long, D. M., Payne, J. D. and Feng, C. (1999) "Information transmission in the Shangai equity market", The Journal of Financial Research, 22, 2945.

[33] Ye, Cai and Mototsugu. Shintoni (2004) "On the Long-Run Variance Ratio Test for a Unit Root" Vanderbilt University, USA 